\title{
A pilot investigation into the influence of electronic cigarettes on oral bacteria
}

\author{
Dominika Cichońska¹, Aida Kusiak¹, Lidia Piechowicz², Dariusz Świetlik³
}

${ }^{1}$ Department of Periodontology and Oral Mucosa Diseases, Medical University of Gdansk, Gdansk, Poland ${ }^{2}$ Department of Medical Microbiology, Faculty of Medicine, Medical University of Gdansk, Gdansk, Poland ${ }^{3}$ Department of IT and Biostatistics, Medical University of Gdansk, Gdansk, Poland

Adv Dermatol Allergol 2021; XXXVIII (6): 1092-1098

DOI: https://doi.org/10.5114/ada.2020.100335

\begin{abstract}
Introduction: Electronic cigarettes have already become a popular alternative to traditional smoking.

Aim: To observe if there were any changes in oral bacteria of electronic cigarette users.

Material and methods: The study population included 125 patients (40 - e-cigarette users, 43 - cigarette smokers, 42 - non-smokers). The conducted microbiological tests were aimed at identification of microorganisms with potential pathological influence on the oral cavity. Distributions of the study variables were compared between groups with $\chi^{2}$ test. All calculations were carried out with Statistical 10 software (Stat Soft Inc.; Tulsa, USA) and intergroup differences were considered significant at $p \leq 0.05$.

Results: The differences were statistically significant in relation to Gram-negative bacteria in e-cigarette users $(27.5 \%)$ compared to smokers of traditional cigarettes $(4.6 \%)(p<0.05)$. In relation to Gram-positive bacteria, no statistically significant differences were found between these groups. Co-occurrence of commensal bacteria and potentially pathogenic bacteria from the oral cavity among e-cigarette users was higher than in smokers of traditional cigarettes ( $32.1 \%$ vs. $9.2 \% ; p<0.05)$.

Conclusions: The use of e-cigarettes caused changes in oral bacteria compared to smokers of traditional cigarettes and non-smokers especially with respect to colonization of potentially pathogenic bacteria. Changes in the oral cavity environment to the disadvantage of commensal flora can affect the course of some pathological processes in the oral cavity.
\end{abstract}

Key words: e-smoking, electronic cigarettes, microbiology, oral bacteria.

\section{Introduction}

Electronic cigarettes, since they appeared 15 years ago, have been becoming more and more widespread among different social groups, which is mainly caused by a wide range of available flavours and ability to control the concentration of nicotine [1-3]. Electronic cigarettes have already become a popular alternative to traditional smoking especially among young people [4-6]. According to numerous research studies, electronic cigarettes are believed to cause less harm, however they are not neutral to the human body [7-9]. At the beginning, electronic cigarettes were also more socially acceptable than traditional cigarettes and allowed to use in public places [7, 10-12]. Usage of electronic cigarettes, in comparison to tobacco smoking, produce less concentration of toxic and carcinogenic substances like carbon monoxide, phenol, polycyclic aromatic carbohydrate and others [13]. Liquids added to electronic cigarettes ex- cept water consist of propylene glycol, nicotine and other additives like glycerol and various flavourings. Aerosol, visible as white fog, is produced by vaporizing e-liquid in the vaporizing chamber to the temperature of about $40-65^{\circ} \mathrm{C}$ $[14,15]$. It has been proven that propylene glycol does not manifest toxic effects and undergoes fast metabolism in the human body [5]. Propylene glycol and glycerine are not detrimental substances, however as a result of chemical reactions during the generation of an aerosol from an ecigarette, they can be transformed into formaldehyde, which is a well-known carcinogen [16]. According to Jensen et al., the amount of formaldehyde formed is similar to its content in tobacco smoke [17]. Another threat associated with the use of electronic cigarettes is posed by flavouring substances, which influence to the human organism still remains unknown. A majority of those substances have already been approved for use in food and cosmetic indus-

Address for correspondence: Dominika Cichońska, Department of Periodontology and Oral Mucosa Diseases, Medical University of Gdansk, 18 Orzeszkowej St, 80-204 Gdansk, Poland, e-mail: dcichonska@gumed.edu.pl Received: 7.07.2020, accepted: 3.08.2020. 
try, nevertheless long-term results of inhaling them might bring serious side effects and is not well examined yet [7, 8, 18-20]. Research conducted by Kucharska et al. exposed discrepancy between the real composition of e-liquids and information given by the manufacturers [21]. In most cases the exact chemical composition of e-liquids is unknown and information received from manufacturers is partial and deficient [22-24]. According to conducted studies, the occurrence of adverse side effects was dependent on the use of specific e-liquid flavours $[25,26]$. Strawberry, coffee and menthol liquids presented significant cytotoxicity to bronchial epithelial cells. However, toxicity of electronic cigarettes is correlated with the device voltage and is stronger after its increase [26].

Firstly, electronic cigarettes were believed to become a less harmful alternative to traditional cigarette smoking, notwithstanding electronic cigarettes could bring serious side effects including xerostomia, cough, increase in breathing resistance, tachycardia and oral cavity disorders [7-9, 27-30]. However, in clinical trials conducted among users of electronic cigarettes, some pathological reactions of the body appearing after smoking a traditional cigarette were not observed including: changes in spirometry parameters, pulse and blood pressure values, myocardial function, carbon monoxide concentration in the exhaled air, nicotine levels in plasma and disorders in the blood cell system, or an increase in the level of inflammatory markers. On the other hand, an increase in respiratory resistance, a decrease in exhaled nitric oxide and oral symptoms in the form of a dry cough, irritation of the mouth and throat have been observed [31, 32]. Research conducted by Farsalinos et al. proved that in comparison to smoking traditional cigarettes, electronic cigarettes did not lead to an increased risk of developing cardiovascular diseases, related to blood pressure values in smokers who replaced traditional cigarettes with electronic ones [33].

The use of electronic cigarettes can also become a cause of numerous side effects related to the oral cavity. In conducted studies there was observed death of oral mucosal epithelial cells by necrosis and apoptosis, regardless of the presence or absence of nicotine in the inhalation solution [34-36]. The cytotoxic effect of e-liquids was also manifested in the induction of oxidative stress [37]. Adverse effects of the usage of electronic cigarettes on periodontal structures have been observed not only by inducing oxidative stress but also by promoting the release of proinflammatory cytokines: PGE2, COX-2, IL-8 $[28,38,39]$. The aerosol generated during the usage of electronic cigarettes adversely affected the maintenance of regular DNA structure, which could potentially lead to the development of mutations and, consequently, a cancer [15, 28].

Research focused on the impact of electronic cigarettes on the condition of the oral cavity still remains limited [15, 28, 34-36, 38, 39].

\section{Aim}

The aim of this study was to observe if there were any changes in oral bacteria among electronic cigarette users in comparison to both non-smokers and people smoking traditional cigarettes.

\section{Material and methods \\ Participants}

One hundred and twenty-five volunteers participated in the study including 40 patients using electronic cigarettes (e-cigarette users), 43 patients smoking traditional cigarettes (smokers) and 42 healthy patients as the control group which have never smoked cigarettes (non-smokers). They all volunteered for a follow-up examination of periodontium and oral mucosa. Patients who participated in this study were not smoking both traditional and electronic cigarettes. All groups included generally healthy people aged 20 to 30 years. Informed consent to participate in the study was obtained from all patients. Underage patients did not participate in the study. Patients with periodontitis and oral mucosa diseases as well as patients with diseases which might interfere the condition of oral mucosa like diabetes, disorders of salivary secretion and patients taking medications permanently and treated with antibiotics or steroid preparations in the last 6 months, were excluded from the research. Electronic cigarette users were using electronic cigarettes with a small nicotine concentration. Traditional cigarette smokers were smoking from 10 to 20 cigarettes per day. The minimum time of using electronic cigarettes and smoking traditional cigarettes was 6 months, the maximum time was 7 months. All groups were also ethnically homogeneous. The study was conducted in 2018-2019. The study protocol has been approved by the Independent Bioethics Committee for Scientific Research at Medical University of Gdansk (NKBBN/161/2014). Ethical aspects of the research followed the World Medical Association Declaration of Helsinki.

\section{Specimen collection and transportation}

The swabs from the oral cavity were collected from all three groups of patients. The samples were obtained with sterile, dry cotton swabs from buccal oral mucosa. Only one swab was collected from each person. The samples were transported to the laboratory in the transport medium (Amies medium, Bionovo, Poland) up to $24 \mathrm{~h}$ and examined immediately thereafter.

\section{Microbiological analysis \\ Culture}

The oral cavity swabs were inoculated directly into Columbia Agar with 5\% Sheep blood, MacConkey agar, Mannitol Salt Agar (MSA) and Sabouraud Dextrose Agar 
(Graso Biotech, Poland) with the use of the isolation streak method to yield a semiquantitative estimate of growth. Blood agar plates (Columbia Agar with 5\% Sheep blood) were incubated in a $\mathrm{CO}_{2}$ jar at $37^{\circ} \mathrm{C}$ for $18-24 \mathrm{~h}$, other plates (MacConkey agar, MSA, Sabouraud Dextrose Agar) were incubated at $37^{\circ} \mathrm{C}$ under aerobic atmosphere, for 24-48 $\mathrm{h}$ [40]. The relative number of organisms was estimated based on the extent of growth beyond the original area of inoculums. Growth in the first quant was graded as 1+, or light growth. Growth in the second or third quadrant was graded as $2+$ to $3+$. Intensity of growth of Streptococcus viridians group and Neisseria sp. ( $N$. sicca, $N$. flavescens) was reported as $2+$ or $3+$; for other microorganisms - growth was estimated as $1+$.

\section{Identification of isolates}

The identification of microorganisms was performed by using conventional microbiological techniques (macroscopic, microscopic, biochemical, serological) [40].

Gram-positive bacterial identification: a) staphylococcal species were identified based on colony morphology, Gram staining technique, tube coagulase test and Microgen Staph test (Microgen Bioproducts Limited, UK); b) Streptococci were identified on the basis of colony characteristics, haemolysis, Gram staining technique, catalase test, optochin sensitivity and Microgen Strep test (Microgen Bioproducts Limited, UK).
Gram-negative bacterial identification was performed biochemically, based on API-system (BioMerieux, Marcyl'Etoile, France). API system was used to determine the identity of other microorganisms. All tests were used according to their manufacturers' instructions. As a commensal flora we accepted microorganisms that are always present in a person in the oral cavity and usually do not cause any disease.

\section{Statistical analysis}

Distributions of the study variables were presented as numbers and percentages and compared between groups with $\chi^{2}$ test. All calculations were carried out with Statistical 10 software (Stat Soft Inc.; Tulsa, USA). Intergroup differences were considered significant at $p \leq 0.05$.

\section{Results}

A total of 298 isolates were identified from both: smokers (e-cigarette users, smokers of cigarettes) and non-smokers. The distribution of microbial isolates in the studied groups is shown in Table 1.

Table 1 shows differences between distribution of microorganisms isolated from electronic cigarette users, smokers of traditional cigarettes and the control group (non-smokers). The incidence of microorganisms other than commensal flora colonizing the oral cavity was significantly higher in electronic cigarette users than in the

Table 1. Distribution of microorganisms isolated from e-cigarette users, smokers of cigarettes and non-smokers

\begin{tabular}{|c|c|c|c|c|}
\hline Microorganisms & $\begin{array}{c}\text { E-cigarette users } \\
n=40\end{array}$ & $\begin{array}{l}\text { Smokers of cigarettes } \\
\qquad n=43\end{array}$ & $\begin{array}{c}\text { Non-smokers } \\
n=42\end{array}$ & $P$-value \\
\hline Commensal bacteria: & 40 (100\%) & $43(100 \%)$ & $42(100 \%)$ & NS \\
\hline Streptococcus viridans group & 40 & 43 & 42 & \\
\hline Neisseria sp. & 40 & 43 & 42 & \\
\hline Staphylococci coagulase- negative & 5 & 2 & 1 & \\
\hline Potentially pathogenic bacteria: & $14(32.1 \%)^{a}$ & $4(9.2 \%)^{b}$ & $14(33.2 \%)$ & $<0.05$ \\
\hline Gram-positive cocci: & $3(4.6 \%)$ & $2(4.6 \%)$ & $7(16.6 \%)$ & NS \\
\hline Streptococcus pyogenes & 0 & 1 & 1 & \\
\hline Staphylococcus aureus & 3 & 1 & 6 & \\
\hline Gram-negative rods: & $11(27.5 \%)^{\mathrm{a}}$ & $2(4.6 \%)^{b}$ & $7(16.6 \%)$ & $<0.05$ \\
\hline Escherichia coli & 3 & 1 & 1 & \\
\hline Klebsiella oxytoca & 1 & 1 & 1 & \\
\hline Klebsiella pneumonia & 1 & 0 & 0 & \\
\hline Enterobacter sp. & 2 & 0 & 1 & \\
\hline Citrobacter sp. & 1 & 0 & 1 & \\
\hline Providentia sp. & 1 & 0 & 1 & \\
\hline Pseudomonas aeruginosa & 2 & 0 & 2 & \\
\hline Candida albicans & $2(5 \%)$ & $2(4.6 \%)$ & $4(9.5 \%)$ & NS \\
\hline
\end{tabular}

${ }^{*} P<0.05$ for $a-b$ (statistical significance), NS - non-significant. 
smokers of cigarettes (15.7\% vs. $6.4 \% ; p<0.05)$. Among the microorganisms colonizing the oral cavity in the tested groups, the most numerous were Gram-negative rods (6.7\%). The Gram-negative rods had a higher percentage of isolation among electronic cigarette users in comparison to traditional smokers of cigarettes (six times lower than in e-cigarette users). The difference is statistically significant $(10.9 \%$ vs. $2.1 \%$; $p<0.05)$, while there were no statistically significant differences in comparison to non-smoker group. Seven different species of Gram-negative rods were isolated from the oral cavity of electronic cigarette users, but among traditional cigarette smokers there were only two.

The frequency of co-isolation of other microorganisms simultaneously with commensal oral flora varied depending on the study group (Table 2) and was more common in a group of electronic cigarette users than in a group of traditional cigarette smokers (40\% vs. $14 \%$; $p<0.05)$. Differences between electronic cigarette users and the control group were not statistically significant, as well as between traditional cigarette smokers and the control group. However, electronic cigarette users occurred to have commensal bacteria reduced $(60 \%)$ only in comparison to traditional cigarette smokers $(86 \%)(p<0.05)$.

The colonization of the oral cavity with one microorganism occurred in all subjects (16/17 vs. 6/6 vs. 9/13). Colonization with two or three microorganisms of this place, in addition to normal flora, was extremely rare in electronic cigarette users and non-smokers. In a group of traditional cigarette smokers there were no colonization with two or more microbial strains.

\section{Discussion}

The presence of physiological flora in the oral cavity is essential for the proper function of the whole organism and any disorder can lead to the development of both oral cavity and general diseases [41]. There are more than 700 bacterial species that inhabit the oral cavity, which makes oral cavity a highly heterogeneous ecosystem [42]. The influence of tobacco smoking is more closely examined than electronic cigarette vapour, however both aspects still need to be explored [43]. In recent studies conducted by Stewart et al. no significant changes in buccal microbiota between traditional cigarette smokers and non-smokers were observed [43], however Yu et al. concluded that buccal diversity of bacteria is reduced among traditional cigarette smokers, which is comparable to our studies [44]. In studies conducted by Yu et al., smoking cigarettes have a strong influence on oral microbiota of buccal mucosa, however there were no statistically significant differences in other parts of the oral cavity between tobacco smokers and non-smokers. In our research, smokers of traditional cigarettes

Table 2. Co-occurrence of commensal bacteria and potentially pathogenic microorganisms from the oral cavity among e-cigarette users, smokers of cigarettes and non-smokers

\begin{tabular}{|c|c|c|c|c|}
\hline Microorganisms & $\begin{array}{c}\text { E-cigarette users } \\
n=40\end{array}$ & $\begin{array}{l}\text { Smokers of cigarettes } \\
\qquad n=43\end{array}$ & $\begin{array}{c}\text { Non-smokers } \\
n=42\end{array}$ & $P$-value \\
\hline Commensal bacteria with potentially pathogenic microorganisms: & $15 / 40(37.5 \%)^{a}$ & $6 / 43(14 \%)^{b}$ & $13 / 42(31 \%)$ & $<0.05$ \\
\hline Commensal bacteria $+S$. aureus & $2 / 40$ & $1 / 43^{\star *}$ & $5 / 42$ & \\
\hline Commensal bacteria $+C$. albicans & $3 / 40^{\star *}$ & $2 / 43$ & $0 / 42$ & \\
\hline Commensal bacteria + Streptococcus pyogenes & $0 / 40$ & $1 / 43^{\star *}$ & $1 / 42$ & \\
\hline Commensal bacteria $+E$. coli & $3 / 40$ & $1 / 43$ & $0 / 42$ & \\
\hline Commensal bacteria + Enterobacter sp. & $2 / 40^{\star *}$ & $2 / 43$ & $1 / 42$ & \\
\hline Commensal bacteria $+K$. oxytoca & $1 / 40$ & $1 / 43^{*}$ & $0 / 42$ & \\
\hline Commensal bacteria $+K$. pneumoniae & $1 / 40$ & $0 / 43$ & $0 / 42$ & \\
\hline Commensal bacteria + Citrobacter sp. & $1 / 40$ & $0 / 43$ & $0 / 42$ & \\
\hline Commensal bacteria + Providencia sp. & $0 / 40$ & $0 / 43$ & $1 / 42$ & \\
\hline Commensal bacteria $+P$. aeruginosa & $1 / 40$ & $0 / 43$ & $1 / 42$ & \\
\hline Commensal bacteria + Providencia sp. + P. aeruginosa & $1 / 40$ & $0 / 43$ & $0 / 42$ & \\
\hline Commensal bacteria + Citrobacter sp. + C. albicans & $0 / 40$ & $0 / 43$ & $1 / 42$ & \\
\hline Commensal bacteria $+S$. aureus $+C$. albicans & $0 / 40$ & $0 / 43$ & $1 / 42^{\star *}$ & \\
\hline Commensal bacteria $+S$. aureus $+K$. oxytoca & $0 / 40$ & $0 / 43$ & $1 / 42$ & \\
\hline Commensal bacteria $+E$. coli $+P$. aeruginosa $+C$. albicans & $0 / 40$ & $0 / 43$ & $1 / 42$ & \\
\hline Commensal bacteria only & $\begin{array}{c}25 / 40 \\
(62.5 \%)^{a}\end{array}$ & $\begin{array}{l}37 / 43 \\
(86 \%)^{b}\end{array}$ & $\begin{array}{l}29 / 42 \\
(69 \%)\end{array}$ & $<0.05$ \\
\hline
\end{tabular}

${ }^{\star} P<0.05$ for $a-b$ (statistical significance), NS - non significant; Commensal bacteria: Streptococcus viridans group,+++ Neisseria sp. ++ (in each sample) and Staphylococci coagulase- negative + (some samples)**. 
presented less diversity of microorganisms in the buccal mucosa, mainly commensal bacteria was observed (86\%), in comparison to the control group (71\%) and ecigarette users (62.5\%). In no sample of traditional cigarette smokers, the presence of Pseudomonas aeruginosa a facultative anaerobic bacterium, was observed, however $P$. aeruginosa appeared among electronic cigarette users and the control group. Differences in the bacteria of the oral cavity between smokers and non-smokers were also observed in studies conducted by Morris et al., where smokers presented a reduction in number of Porphyromonas, Neisseria and Gemella [45]. However Wu claimed to observe a reduction in Proteobacteria occurrence among cigarette smokers [46].

The impact of electronic cigarette usage on oral bacteria is an issue that has not been the subject of comprehensive research yet, except for single research conducted in 2018 by Stewart et al., where no important changes in oral bacteria diversity among electronic cigarette users in comparison to non-smokers were proven, however the research included a smaller study group (30 individuals) [43] than our research. In the test results which we received in a group of 125 individuals, among e-cigarette users there was observed higher co-occurrence of commensal flora and other microorganisms colonizing the oral cavity than among smokers of traditional cigarettes (15.7\% vs. $6.4 \%$; $p<0.05)$ and the control group (non-smokers). There was also a statistically significant increase in Gram-negative rods among e-cigarette users and traditional cigarette smokers. Mainly Gram-negative fermentative rods were isolated. These bacteria may temporarily colonize the upper respiratory tract, however in hospitalized patients under artificial respiration they can develop a difficult-totreat pneumonia. In our research there were no statistically significant differences in presence of Candida albicans in all groups. On the contrary, research conducted by Mokeem revealed more frequent colonization of the oral cavity by Candida spp. among both electronic cigarette users and traditional cigarette smokers in comparison to non-smokers [47]. Due to the considerable differences in obtained results, further research is required.

The usage of electronic cigarettes causes changes in the oral cavity environment to the disadvantage of commensal flora, which can lead to development of some pathological processes in the oral cavity, for instance oral mucositis. This is the most widely observed side effect of non-surgical cancer treatment, which concerns $75 \%$ of high risk patients subjected to head and neck radiotherapy or high-dose chemotherapy $[48,49]$. Reduction in the amount of pathological microorganisms inhabiting the oral cavity is an important issue in management of oral mucositis. This is not an infectious disease however secondary colonization of ulcerations pose a negative influence on mucosal healing processes [50].

An important factor which significantly influences maintenance of healthy oral bacteria is saliva. All disor- ders connected with secretion and composition of saliva may lead to changes in composition of oral bacteria [51]. Electronic cigarettes and tobacco smoking influence antibacterial properties of saliva. Saliva of e-cigarette users and tobacco smokers presented a lower lysozyme level in, which have bacteriolytic properties in gram-positive bacteria and can activate destruction of bacterial cell walls. However, tobacco smokers were also observed to have a lower level of IgA and lactoferrin in saliva. On the contrary, in saliva of electronic cigarette users there was a higher level of lactoferrin and no changes in IgA [52]. Those changes in composition of saliva may also influence the presence of bacteria in the oral cavity.

The conducted research has its limitations resulting from a small number of the studied groups, however due to the homogeneity of the groups, the obtained results are reliable. The issue of using electronic cigarettes still requires some further longitudinal study on an even larger group of respondents.

\section{Conclusions}

The oral cavity, being the first link in contact with tobacco smoke and aerosol of electronic cigarettes, is an area particularly vulnerable to the potentially harmful effects of inhaled substances. Our research revealed changes in the oral bacteria in comparison to the control group for both smokers and e-cigarette users. The usage of electronic cigarettes causes changes in the oral cavity environment to the disadvantage of commensal flora, which can affect the course of some pathological processes in the oral cavity. However, the differences were greater in the group of people using electronic cigarettes compared to people smoking traditional cigarettes, especially in colonization of other microorganisms which especially in hospitalized patients may contribute to the development of a life-threatening disease.

The impact of electronic cigarettes on oral bacteria still remains a poorly understood issue that requires further research and longitudinal study on a larger study group of patients.

\section{Conflict of interest}

The authors declare no conflict of interest.

\section{References}

1. Pepper JK, Ribisl KM, Brewer NT. Adolescents' interest in trying flavoured e-cigarettes. Tob Control 2016; 25: 62-6.

2. Brown J, West R, Beard E, et al. Prevalence and characteristics of e-cigarette users in Great Britain: findings from a general population survey of smokers. Addict Behav 2014; 39: 1120-5.

3. Etter JF, Bullen C. A longitudinal study of electronic cigarette users. Addict Behav 2014; 39: 491-4. 
4. Smith DM, Gawron M, Balwicki L, et al. Exclusive versus dual use of tobacco and electronic cigarettes among adolescents in Poland, 2010-2016. Addict Behav 2019; 90: 341-8.

5. Kusiak A, Chomyszyn-Gajewska M, Pietruska M, et al. Analysis of electronic cigarette use among Polish dental students. Dent Med Probl 2017; 54: 263-6.

6. Maj A, Kusiak A, Wojtaszek-Slominska A, et al. Electronic cigarettes use among 10-11-years old: preliminary report. Dental Forum 2018; 46: 31-4.

7. Bertholon JF, Becquemin MH, Annesi-Maesano I, et al. Electronic cigarettes: a short review. Respiration 2013; 86: 433-8.

8. Holliday R, Stubbs C. A dental perspective on electronic cigarettes: the good, the bad and the ugly. Oral Health 2015; 6: 16-26.

9. Pisinger C, Dossing M. A systematic review of health effects of electronic cigarettes. Prev Med 2014; 69: 248-60.

10. Ayers JW, Ribisl KM, Brownstein JS. Tracking the rise in popularity of electronic nicotine delivery systems (electronic cigarettes) using search query surveillance. Am J Prev Med 2011; 40: 448-53.

11. Goniewicz ML, Gawron M, Nadolska J, et al. Rise in electronic cigarette use among adolescents in Poland. J Adolesc Health 2014; 55: 713-5.

12. Etter JF, Bullen C. Electronic cigarette: users profile, utilization, satisfaction and perceived efficiency. Addiction 2011; 106: 2017-28.

13. McKee M, Capewell S. Evidence about electronic cigarettes: a foundation built on rock or sand? Br Med J 2015; 351: 48-63.

14. McNeill A, Brose LS, Calder R, et al. E-cigarettes: an evidence update. A report commissioned by Public Health England 2015.

15. Brown CJ, Cheng JM. Electronic cigarettes: product characterization and design considerations. Tob Control 2014; 23 : 4-10.

16. Jensen RP, Luo W, Pankow JF, et al. Hidden formaldehyde in e-cigarettes aerosols. N Engl J Med 2015; 372: 392-4.

17. Kosmider L, Sobczak A, Fik M, et al. Carbonyl compounds in electronic cigarette vapors: effects of nicotine solvent and battery output voltage. Nicotine Tob Res 2014; 16: 1319-26.

18. Khlystov A, Samburova V. Flavoring compounds dominate toxic aldehyde production during E-cigarette vaping. Environ Sci Technol 2016; 50: 13080-5.

19. Ingebrethsen BJ, Cole SK, Alderman SL. Electronic cigarette aerosol particle size distribution measurements. Inhal Toxicol 2012; 24: 976-84.

20. Tierney PA, Karpinski CD, Brown JE, et al. Flavour chemicals in electronic cigarette fluids. Tob Control 2016; 25: 10-5.

21. Kucharska M, Wesolowski W, Czerczak S, et al. Testing of the composition of e-cigarette liquids - manufacturer-declared vs. true contents in a selected series of products. Med $\mathrm{Pr}$ 2016; 67: 239-53.

22. Williams M, Villarreal A, Bozhilov K, et al. Metal and silicate particles including nanoparticles are present in electronic cigarette cartomizer fluid and aerosol. PLoS One 2013; 8: e57987.

23. Goniewicz ML, Knysak J, Gawron M, et al. Levels of selected carcinogens and toxicants in vapor from electronic cigarettes. Tob Control 2014; 23: 133-9.

24. Cheng T. Chemical evaluation of electronic cigarettes. Tob Control 2014; 23: 11-7.

25. Inkielewicz-Steppniak I, Kusiak A, Wojtaszek-Słomińska A, et al. The impact of electronic cigarette liquids on human gingival cell viability - a preliminary in vitro study. Dental Forum 2016; 1: 17-20.
26. Leigh NJ, Lawton RI, Hershberger PA, et al. Flavorings significantly affect inhalation toxicity of aerosol generated from electronic nicotine delivery systems (ENDS). Tob Control 2016; 25: 81-7.

27. Burstyn I. Peering through the mist: systematic review of what the chemistry of contaminants in electronic cigarettes tells us about health risks. BMC Public Health 2014; 9: 18.

28. Sundar IK, Javed F, Romanos GE, et al. E-cigarettes and flavorings induce inflammatory and pro-senescence responses in oral epithelial cells and periodontal fibroblasts. Oncotarget 2016; 7: 77196-204.

29. Ji EH, Sun B, Zhao T, et al. Characterization of electronic cigarette aerosol and its induction of oxidative stress response in oral keratinocytes. PLoS One 2016; 11: e0169380.

30. Hua M, Alfi M, Talbot P. Health-related effects reported by electronic cigarette users in on line forums. J Med Internet Res 2013; 15: e59.

31. Callahan-Lyon P. Electronic cigarettes: human health effects Tob Control 2014; 23: 36-40.

32. Dinakar C, O'Connor G. The health effects of electronic cigarettes. N Engl J Med 2016; 375: 1372-81.

33. Farsalinos K, Cibella F, Caponnetto $P$, et al. Effect of continuous smoking reduction and abstinence on blood pressure and heart rate in smokers switching to electronic cigarettes. Intern Emerg Med 2016; 11: 85-94.

34. Yu V, Rahimy M, Korrapati A. Electronic cigarettes induce DNA stand breaks and cell death independently of nicotine in cell lines. Oral Oncol 2016; 52: 58-65.

35. Semlali A, Chakir J, Goulet JP, et al. Whole cigarette smoke promotes human gingival epithelial cell apoptosis and inhibits cell repair processes. J Periodontal Res 2011; 46: 533-41.

36. Rouabhia M, Park HJ, Semlali A, et al. E-cigarette vapour induces an apoptotic response in human gingival epithelial cells through the caspase-3 pathway. J Cell Physiol 2017; 232: 1539-47.

37. Holliday R, Kist R, Bauld L. E-cigarette vapour is not inert and exposure can lead to cell damage. Evid Based Dent 2016; 17: 2-3.

38. Meo SA, Al Asiri SA. Effects of electronic cigarette smoking on human health. Eur Rev Med Pharmacol Sci 2014; 18: 3315-9.

39. Cervellati F, Muresan X, Sticozzi C, et al. Comparative effects between electronic and cigarette smoke in human keratinocytes and epithelial lung cells. Toxicol In Vitro 2014; 28 999-1005.

40. Winn WC Jr, Allen S, Janda W, et al. Koneman's Color Atlas and Textbook of Diagnostic Microbiology. $6^{\text {th }}$ ed. Lippincott Williams and Wilkins, Philadelphia 2006.

41. Yamashita Y, Takeshita T. The oral microbiome and human health. J Oral Sci 2017; 59: 201-6.

42. Chen T, Yu WH, Izard J, et al. The Human Oral Microbiome Database: a web accessible resource for investigating oral microbe taxonomic and genomic information. Database (Oxford) 2010; 2010: baq013. doi:10.1093/database/baq013.

43. Stewart CJ, Achtung TA, Ajami NJ, et al. Effects of tobacco smoke and electronic cigarette vapour exposure on the oral and gut microbiota in humans: a pilot study. Peer J 2018; 30: e4693.

44. Yu G, Phillips S, Gail MH, et al. The effect of cigarette smoking on the oral and nasal microbiota. Microbiome 2017; 5: 3.

45. Morris A, Beck JM, Schloss PD, et al. Comparison of the respiratory microbiome in healthy nonsmokers and smokers. Am J Respir Crit Care Med 2013; 187: 1067-75. 
46. Wu J, Peters BA, Dominianni C, et al. Cigarette smoking and the oral microbiome in a large study of American adults. ISME J 2016; 10: 2435-46.

47. Mokeem SA, Abduljabbar T, Al-Kheraif AA, et al. Oral Candida carriage among cigarette- and waterpipe-smokers, and electronic-cigarette users. Oral Dis 2019; 25: 319-26.

48. Al-Dasoogi N, Sonis ST, Bowen JM, et al Emerging evidence on the pathobiology of mucositis. Support Care Cancer 2013; 21: 3233-41.

49. Scully C, Sonis S, Diz PD. Oral mucositis. Oral Dis 2006; 12: 229-41.

50. Sonis ST. Oral Mucositis. Springer Healthcare, Berlin 2012.

51. LyngePedersen AM, Belstrøm D. The role of natural salivary defences in maintaining a healthy oral microbiota. J Dent 2019; 80: 3-12.

52. Cichońska D. Kusiak A. Kochańska B, et al. Influence of electronic cigarettes on selected antibacterial properties of saliva. Int J Environ Res Public Health 2019; 16: 4433. 